This is a pre-copy-editing, author-produced PDF of an article accepted for publication in Nicotine \& Tobacco Research following peer review. The definitive publisher-authenticated version [Shahab, L. \& West, $R$. (2009). Do ex-smokers report feeling happier following cessation? Evidence from a cross-sectional survey. Nicotine \& Tobacco Research, 11, 553-557.] is available online at: http://ntr.oxfordjournals.org/content/11/5/553.long 


\title{
Do ex-smokers report feeling happier following cessation? Evidence from a cross-sectional survey
}

\author{
Lion Shahab, $\mathrm{PhD}$; Robert West, $\mathrm{PhD}$
}

Cancer Research UK Health Behaviour Research Centre, Department of Epidemiology and Public Health, University College London, 2-16 Torrington Place, London, WC1E 6BT, UK.

Corresponding author:

Dr Lion Shahab, Cancer Research UK Health Behaviour Research Centre, Department of Epidemiology \& Public Health, University College London, 2-16 Torrington Place, London, WC1E 6BT, UK; Phone: +44 207679 6495; Fax: +44 2078132848

Email: lion.shahab@ucl.ac.uk

Abstract word count: 250

Manuscript word count: 2044

Pages: 15

Figures: 1

Tables: 2 


\begin{abstract}
Background: Many smokers fear that they will give up an important source of enjoyment when they stop smoking and be less happy. Yet, little is known about the long-term affective impact of quitting. This study examined ex-smokers' reports of change in happiness following cessation and factors associated with these reports.
\end{abstract}

Method: In a cross-sectional household survey of a randomly selected, representative sample, 879 ex-smokers were asked to indicate whether they felt happier now, less happy or about the same as when they were smoking. In addition to sociodemographic variables, the survey assessed how long ago ex-smokers had stopped as well as prior enjoyment of smoking.

Results: The large majority of ex-smokers $(69.3 \%, 95 \%$ CI 66.2-72.3) reported feeling happier now than when they were smokers, and only a very small minority $(3.3 . \%$, 95\%CI 2.2-4.7) reported feeling less happy. In multiple regression analysis, controlling for all other variables, greater happiness following cessation was associated with being younger (OR per 10 year increase in age: 3.31; 95\%CI 1.666.62) and having quit more than a year ago (OR 2.59; 95\%CI 1.58- 4.24) but responses were not related to other socio-demographic factors, prior cigarette consumption or previous enjoyment of smoking. Irrespective of these associations, in every given category of respondents the majority of ex-smokers reported being happier having quit smoking.

Conclusions: Ex-smokers overwhelmingly report being happier now than when they were smoking. This may be for many reasons, including self-justification, but it provides at least partial reassurance to would-be quitters that quality of life is likely to improve if they succeed.

Key words: smoking, smoking cessation, happiness, quality of life 


\section{Introduction}

A major concern of smokers thinking about stopping is that they will be giving up an important source of enjoyment and a tool for coping with life's stresses and strains (Lader, 2007): in short, they will be less happy. Even smokers attempting to stop as part of a clinic programme report that enjoyment is an important part of their smoking (West, 2006a). Yet, many smokers are disenchanted with smoking and the majority regret having started in the first place (Jarvis, McIntyre, Bates, \& Foulds, 2002). Moreover, although the causal relationship between depression and smoking is unclear (Steuber \& Danner, 2006), surveys consistently show that smokers have higher levels of depression than never or ex-smokers and that taking up smoking is followed by an increase in rates of clinical depression (West \& Jarvis, 2005).

Cross-sectional studies of diurnal variation in mood that compare never with current smokers show lower levels of happiness in the latter group across the day (Adan \& Sanchez-Turet, 2000). While smoking after a short period of abstinence is usually associated with an improvement in self-reported mood (Dawkins, Acaster, \& Powell, 2007) and a decrease in stress levels (O'Neill \& Parrott, 1992), this is consistent with a deprivation-reversal model (Schachter, 1978), The model suggests that rather than genuinely improving stress and mood levels, smoking a cigarette simply restores normal mood by reversing the psychological and physiological effects of deprivation (McNeill, Jarvis, \& West, 1987). In agreement with this interpretation, smokers usually report above-average stress pre-smoking and only average stress levels postsmoking in comparison with non-smokers (Parrott, 1994). Besides research on the association of short- or long-term abstinence with stress levels or mood changes (Cohen \& Lichtenstein, 1990), much less is known about longer term effects of 
smoking cessation on self-reported happiness. Indeed, a recent article in the Journal of Happiness Studies found only a handful of studies looking at this associations (Veenhoven, 2003) - some reporting no, others a negative, correlation between smoking and happiness.

Given that the notion of 'happiness' has vexed philosophers for centuries (Haybron, 2003), the lack of research in this area probably arises from problems in defining such an elusive, multifaceted concept. In health research happiness is often subsumed under the umbrella term 'Quality of Life' to indicate global life satisfaction and is therefore different from the momentary assessment of a subjective emotional state such as positive or negative mood. Associated with the issue of defining happiness is its operationalisation. There are doubts concerning the validity and reliability of selfreport to assess happiness as people may be systematically biased in their answers, have a limited understanding of their emotions or the terms used to communicate them and consequently be capricious in their responses. However, what research exists indicates that a single, direct question does as well as ratings based on in-depth interviews providing relatively reliable and culture-free responses (Veenhoven, 1997).

Despite these general caveats, research has started to accumulate investigating the relationship between happiness and health, usually reporting an association of greater happiness with good health outcomes (Pressman \& Cohen, 2005) and with reductions in intermediary correlates such as neuroendocrine or inflammatory markers (Steptoe, Wardle, \& Marmot, 2005). As smoking is linked to increased levels of these markers and thus to increased health risks (Danesh, Collins, Appleby, \& Peto, 1998), the impact of smoking cessation on the subsequent health of ex-smokers may also be 
influenced by changes in happiness levels and more needs to be known about this relationship. As a first attempt to examine these issues directly, we used crosssectional survey data to investigate whether ex-smokers report that they are happier, the same or less happy now than when they were smoking and to explore correlates of their responses.

\section{Methods}

\section{$\underline{\text { Procedure }}$}

Data come from the Smoking Toolkit Study. This comprises a series of crosssectional household-based surveys carried out by the social research company BMRB following an established quota sampling method (with respect to age, sex, social grade, region, working status and presence of children). Methodological details are provided elsewhere (West, 2006b). Briefly, a face-to-face household survey was conducted using random location sampling in Census based Output Areas. Derived sample units are stratified by characteristics and region and randomly selected with a probability of selection proportional to their population to provide a nationally representative sample. One face-to-face interview was carried out per selected household using a Computer Assisted Personal Interviewing system to increase reliability and eliminate interviewer error.

\section{$\underline{\text { Participants }}$}

Participants were eligible for inclusion if they resided in England and were 16 years of age or over at the time of the interview. In this nationally representative sample of 5386 adults, the majority had never smoked (58.4\%) while about a quarter (25.4\%) currently smoked. The remaining $16.3 \%$ of the sample who identified themselves as 
ex-smokers were included in the analysis. Among these 879 ex-smokers, 103 (11.7\%) had stopped within the last year and $776(88.3 \%)$ had stopped more than a year ago. Table 1 provides demographic and smoking characteristics of the sample of exsmokers.

\section{$\underline{\text { Measures }}$}

The interviewer recorded demographic information. Smoking status was assessed by asking participants if they (a) smoked cigarettes (including hand-rolled) every day; (b) smoked cigarettes (including hand-rolled) but not every day; (c) did not smoke cigarettes at all but did smoke tobacco of some kind (e.g. pipe or cigar); (d) had stopped smoking completely in the last year; (e) had stopped smoking completely more than a year ago; or (f) had never been a smoker (i.e. smoked for a year or more). Those participants who responded 'yes' to (d) or (e) were further asked which of the following statements best applied to them: 'I feel happier now than when I was smoking'; 'I feel about the same now as when I was smoking'; 'I feel less happy now than when I was smoking'. This form of questioning was adapted to minimise response bias that might lead to an affirmative answer to a question of the kind 'Do you feel happier now than when you were smoking?' Recognising that they may not feel able to answer this question, participants were given the option of saying that they did not know.

All participants responding 'yes' to questions (a) through (e) were also asked to indicate how many cigarettes per day/week/month they usually smoked. Respondents were further asked how much they had enjoyed smoking with response options being: 'Very much', 'quite a bit', 'not particularly', 'not at all' and 'don't know'. 


\section{$\underline{\text { Analysis }}$}

Data were analysed using SPSS 14.0. Simple associations between happiness responses and predictor variables were assessed with $\mathrm{X}^{2}$ analysis. As this analysis was exploratory all variables, irrespective of univariate associations, were included in a multiple logistic regression to evaluate which, if any, of the assessed variables independently predicted reports of being happier versus being the same or less happy following cessation.

\section{Results}

This sample of ex-smokers contained relatively more people in older than younger age groups; more than half were above 55 years of age and female (Table 1). The majority were employed in managerial, administrative or professional jobs. Just over half of ex-smokers reported consuming at least 11 cigarettes per day and a quarter reported not having enjoyed smoking previously.

The overwhelming majority of ex-smokers $(69.3 \%, 95 \%$ CI $66.2-72.3)$ reported being happier now than when they were smoking; around a quarter reported feeling the same $(26.6 \%, 95 \%$ CI $23.7-29.5)$ and very few were less happy now than when they smoked $(3.3 \%, 95 \% \mathrm{CI} 2.2-4.7)$. With the exception of seven respondents, all exsmokers felt able to answer this question.

There was no evidence for overall sex differences in self-reported happiness $\left(X^{2}(3)=4.1, \mathrm{p}=.252\right)$; neither were there any differences in happiness according to exsmokers' previous cigarette consumption $\left(X^{2}(9)=12.4, \mathrm{p}=.192\right)$. Although the 
distribution of responses on self-reported happiness differed by socio-economic group $\left(X^{2}(12)=23.2, \mathrm{p}=.026\right)$, there was no linear, interpretable trend.

When looking at self-reported happiness in terms of the length of time since quitting, ex-smokers who had stopped more than a year ago were happier now but the difference was not statistically significant $\left(X^{2}(3)=7.0, \mathrm{p}=.072\right)$. Irrespective of the length of time of quitting, the majority of ex-smokers in each category reported feeling happier now than when they were smoking (Figure).

Self-reported happiness was marginally associated with age $\left(X^{2}(15)=26.4, \mathrm{p}=.05\right)$. The younger ex-smokers were, they more likely they were to report feeling happier since having stopped smoking. However, in each age group, most ex-smokers felt happier now rather than the same or less happy compared with when they were smokers.

As might be expected, smokers reporting that they had enjoyed smoking more were less likely to report being happier having stopped $\left(X^{2}(9)=33.2, \mathrm{p}<.001\right)$. However, in multiple logistic regression analysis with all socio-demographic and smoking-related predictors entered together, this association was attenuated and the only clear significant predictors of greater self-reported happiness were being younger and having stopped more than a year ago (see Table 2).

\section{Discussion}

This cross-sectional study provides a preliminary exploration of the relationship between self-reported happiness and stopping smoking. The large majority of exsmokers considered themselves to be happier having stopped smoking. This does not 
necessarily mean that smokers were actually happier and neither does it offer a reason why they were happier. However, the fact that the respondents considered themselves to be happier makes it unlikely that they were actually more miserable. It is also noteworthy that only a small minority, even of the smokers who reported that they had enjoyed smoking a lot, reported being less happy.

A number of possible explanations could be put forward for our results. Smokers who were less happy may have relapsed and future research could monitor happiness levels longitudinally from the quit attempt onwards to evaluate whether this is the case. In the multivariate analysis there was evidence that ex-smokers who had quit for a longer period of time were more likely to report feeling happier compared with those who had quit more recently. However, response differences were relatively small and even among recent ex-smokers, the majority reported feeling happier now than when they were smokers.

Another explanation is that interviewers may have influenced participants to respond positively or that respondents were just telling the researcher that they were happier because they believed that would create a more favourable impression. However, given the methodological rigour of the study to avoid response biases (standardising interviews, training of interviewers), this is unlikely to have had a large impact on results. Moreover, even ex-smokers who admitted to having enjoyed smoking a lot (and thus arguably were less intend on creating a favourable impression), reported that they were happier now and very few were less happy. A third reason for our findings may be recall bias. Respondents could be motivated to feel happier as a result of selfjustification for their decision to stop smoking or because people generally report 
feeling happier in the present than in the past. We cannot rule out this explanation but it would not negate the fact that they did actually feel happier for whatever reason. Indeed, while some studies suggest that people may downplay past happiness (McFarland \& Alvaro, 2000), there is not only evidence to suggest that subjective well-being is relatively stable over time (Blanchflower \& Oswald, 2004; Lucas, Clark, Georgellis, \& Diener, 2003) but that real improvements in happiness levels are possible (Lucas, 2007).

A fourth possibility is the ex-smokers were happier because they felt empowered by what they had achieved and this issue merits further research. Finally, it is feasible that ex-smokers are happier because they no longer suffer from the adverse psychological effects of smoking; this may also explain why smokers who have quit longer ago report being happier. This suggestion is supported by previous studies showing that stopping smoking reduces, rather than increases, anxiety (West \& Hajek, 1997) and stress (Cohen \& Lichtenstein, 1990).

This study was limited being cross-sectional and in adopting a single direct measure of change in happiness. Assessing, and conceptualising, happiness is fraught with difficulties even though most people have a strong intuitive sense of what it is (Veenhoven, 1997). A better approach is to assess happiness, and associated changes following cessation, longitudinally in sample comprising smokers, ex-smokers and never smokers. This would allow disentangling temporal changes in happiness as well as changes according to smoking status. However, in the absence of relevant work in this area, the current study provides a first base from which to develop further research investigating this important issue. The results were strikingly positive and 
while no causal conclusions can be drawn they provide some tentative implications for clinical practice: if smokers can be reassured that their lives are likely to become happier when they stop smoking, this could remove a significant barrier for attempting to quit.

\section{Funding}

This study was funded by Cancer Research UK, Pfizer, GlaxoSmithKline and Johnson and Johnson.

\section{Competing interests}

Lion Shahab has received an honorarium for a talk and travel expenses from a pharmaceutical company making smoking cessation products. Robert West undertakes research and consultancy for developers and manufacturers of smoking cessation treatments such as nicotine replacement products. 


\title{
References
}

\author{
Reference List
}

Adan, A. \& Sanchez-Turet, M. (2000). Effects of smoking on diurnal variations of subjective activation and mood. Human Psychopharmacology, 15, 287-293.

Blanchflower, D. G. \& Oswald, A. J. (2004). Well-being over time in Britain and the USA. Journal of Public Economics, 88, 1359-1386.

Cohen, S. \& Lichtenstein, E. (1990). Perceived stress, quitting smoking, and smoking relapse. Health Psychology, 9, 466-478.

Danesh, J., Collins, R., Appleby, P., \& Peto, R. (1998). Association of fibrinogen, Creactive protein, albumin, or leukocyte count with coronary heart disease: metaanalyses of prospective studies. Journal of the American Medical Association, 279, $1477-1482$.

Dawkins, L., Acaster, S., \& Powell, J. H. (2007). The effects of smoking and abstinence on experience of happiness and sadness in response to positively valenced, negatively valenced, and neutral film clips. Addictive Behaviors, 32, 425-431.

Haybron, D. M. (2003). What do we want from a theory of happiness?

Metaphilosophy, 34, 305-329.

Jarvis, M. J., McIntyre, D., Bates, C., \& Foulds, J. (2002). Effectiveness of smoking cessation initiatives. Efforts must take into account smokers' disillusionment with smoking and their delusions about stopping. British Medical Journal, 324, 608.

Lader, D. (2007). Smoking-related Behaviour and Attitudes, 2006. London: Office for National Statistics.

Lucas, R. E. (2007). Adaptation and the set-point model of subjective well-being Does happiness change after major life events? Current Directions in Psychological Science, 16, 75-79.

Lucas, R. E., Clark, A. E., Georgellis, Y., \& Diener, E. (2003). Reexamining adaptation and the set point model of happiness: reactions to changes in marital status. Journal of Personality and Social Psychology, 84, 527-539.

McFarland, C. \& Alvaro, C. (2000). The impact of motivation on temporal comparisons: coping with traumatic events by perceiving personal growth. Journal of Personality and Social Psychology, 79, 327-343.

McNeill, A. D., Jarvis, M., \& West, R. (1987). Subjective effects of cigarette smoking in adolescents. Psychopharmacology, 92, 115-117.

O'Neill, S. T. \& Parrott, A. C. (1992). Stress and arousal in sedative and stimulant cigarette smokers. Psychopharmacology, 107, 442-446. 
Parrott, A. C. (1994). Acute pharmacodynamic tolerance to the subjective effects of cigarette smoking. Psychopharmacology, 116, 93-97.

Pressman, S. D. \& Cohen, S. (2005). Does positive affect influence health?

Psychological Bulletin, 131, 925-971.

Schachter, S. (1978). Pharmacological and psychological determinants of smoking. In R.Thornton (Ed.), Smoking Behaviour, Physiological and Psychological Influences ( Edinburgh: Churchill-Livingston.

Steptoe, A., Wardle, J., \& Marmot, M. (2005). Positive affect and health-related neuroendocrine, cardiovascular, and inflammatory processes. Proceedings of the National Academy of Sciences of the United States of America, 102, 6508-6512.

Steuber, T. L. \& Danner, F. (2006). Adolescent smoking and depression: which comes first? Addictive Behaviors, 31, 133-136.

Veenhoven, R. (1997). Advances in Understanding Happiness. Revue Québécoise de Psychologie, 18, 29-79.

Veenhoven, R. (2003). Hedonism and Happiness. Journal of Happiness Studies, 4, 437-457.

West, R. (2006a). Defining and assessing nicotine dependence in humans. In G.Bock \& J. Goode (Eds.), Understanding Nicotine and Tobacco Addiction (pp. 36-51). London: Wiley.

West, R. (2006b). Smoking toolkit study: protocol and methods. www.smokinginengland.info/Ref/paperl.pdf.

West, R. \& Hajek, P. (1997). What happens to anxiety levels on giving up smoking? The American Journal of Psychiatry, 154, 1589-1592.

West, R. \& Jarvis, M. J. (2005). Tobacco smoking and mental disorder. Italian Journal of Psychiatry and Behavioural Sciences, 15, 10-17. 


\section{Tables}

Table 1: Sample characteristics

\begin{tabular}{crc}
\hline & \multicolumn{2}{c}{$\begin{array}{r}\text { Total Sample } \\
(\mathrm{N}=879)\end{array}$} \\
\hline$\%$ (N) Age & 4.4 & $(39)$ \\
$16-24$ & 12.5 & $(110)$ \\
$25-34$ & 15.8 & $(139)$ \\
$35-44$ & 14.6 & $(128)$ \\
$45-54$ & 18.7 & $(164)$ \\
$55-64$ & 34.0 & $(299)$ \\
$65+$ & 51.1 & $(449)$ \\
\% (N) Women & & \\
\% (N) Social Group & 21.7 & $(191)$ \\
AB & 29.2 & $(257)$ \\
C1 & 23.8 & $(209)$ \\
C2 & 10.5 & $(92)$ \\
D & 14.8 & $(130)$ \\
E & & \\
\% (N) Smoking cessation & 11.7 & $(103)$ \\
$\leq 1$ year ago & 88.3 & $(776)$ \\
$>1$ year ago & & \\
\% (N) Cigarettes per day ${ }^{\ddagger}$ & 40.9 & $(335)$ \\
$1-10$ & 38.4 & $(315)$ \\
$11-20$ & 8.9 & $(73)$ \\
$21-30$ & 11.8 & $(97)$ \\
31+ & & \\
\% (N) Smoking enjoyment & 27.9 & $(245)$ \\
Very much & 48.2 & $(424)$ \\
Quite a bit & 20.7 & $(182)$ \\
Not particularly & 2.7 & $(24)$ \\
Not at all & 0.4 & $(4)$ \\
Don't know & &
\end{tabular}

${ }^{\S} \mathrm{AB}=$ Higher and intermediate managerial/administrative/professional, $\mathrm{C} 1=$ Supervisory, clerical, junior managerial/administrative/professional, $\mathrm{C} 2=$ Skilled manual workers, $\mathrm{D}=$ Semi-skilled and unskilled manual workers, $\mathrm{E}=\mathrm{On}$ state benefit, unemployed, lowest grade workers; ${ }^{\star 59}$ cases missing

Table 2: Regression analysis, adjusted odds ratio (95\% confidence interval)

\begin{tabular}{lc}
\hline Predictors & $\begin{array}{c}\text { Happier now versus same } \\
\text { /less happy }\end{array}$ \\
\hline Age $^{\mathrm{a}}$ & $1.21(1.09-1.35)$ \\
$\mathrm{Sex}^{\mathrm{b}}$ & $0.86(0.62-1.18)$ \\
Social Group $^{\mathrm{c}}$ & $1.03(0.92-1.16)$ \\
Time since smoking cessation $^{\mathrm{d}}$ & $2.37(1.48-3.80)$ \\
Cigarettes per day $^{\mathrm{e}}$ & $1.07(0.90-1.27)$ \\
Smoking enjoyment $^{\mathrm{f}}$ & $0.80(0.64-1.00)$ \\
\hline
\end{tabular}

${ }^{a}$ Decreasing in 10 year increments; ${ }^{b}$ Female versus male (referent);

${ }^{\mathrm{c}}$ Increasing from social group $\mathrm{AB} ;{ }^{\mathrm{d}} \mathrm{Quit}$ more than a year ago versus quit within past year (referent); ${ }^{\mathrm{e}}$ Increasing in increments of 10 cigarettes per day; ${ }^{f}$ Increasing from 'not at all' 
Figure: Self-reported happiness following smoking cessation by length of abstinence

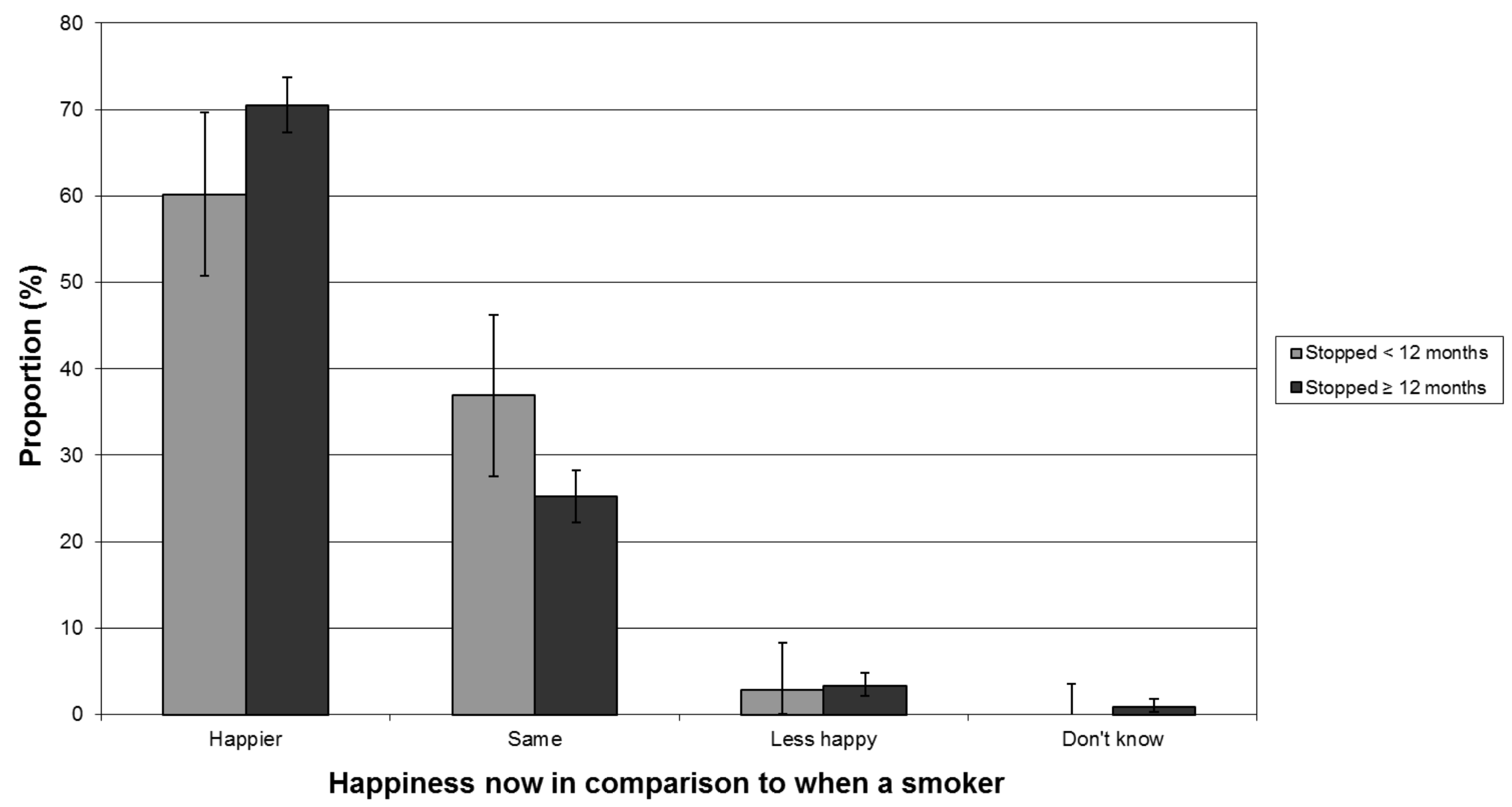

